\title{
Neuroimaging in Children with Cerebral Palsy: A Study Conducted at Tertiary Level Paediatric Hospital of Nepal
}

\author{
Manandhar BP', Singh $\mathbf{U}^{2}$, Khatun $\mathbf{N}^{3}$
}

\begin{abstract}
Introduction: In Nepal, cerebral palsy (CP) is the common cause of severe motor disability. However, only few descriptive studies related to it have been conducted, but those did not incorporate neuroimaging in CP. Thus, the objective of this study is to identify clinical and radiological profile of children diagnosed with $\mathrm{CP}$ at a tertiary level paediatric hospital of Nepal. Material and Methods: This study was carried out at Kanti Children's Hospital and the study utilized data of children diagnosed with CP from September 2015- April 2017. Results: A total of 100 children were diagnosed with CP. Spastic CP was the most common in children $(71 \%)$, followed by mixed $(21 \%)$ and dyskinetic ( $8 \%)$. Majority of the children were male (74\%), born at term (90\%) and delivered at institution (80\%). Neuroimaging abnormality was found in $66 \%$ of cases which included brain malformation (2\%), periventricular white matter abnormalities (23\%), cortical or deep grey matter lesions (37\%) and miscellaneous (4\%). The results of this study also showed significant association between variables such as birth weight and birth asphyxia with type of neuroimaging findings. Conclusion: Neuroimaging is helpful for diagnosis of CP and also useful for parents and physicians to understand children condition. Hence, further studies related to neuroimaging in $\mathrm{CP}$ are important to better understand it in detail.
\end{abstract}

Key words: Cerebral Palsy, Neuroimaging, Birth asphyxia

\section{Introduction}

C erebral palsy $(\mathrm{CP})$ is common cause of severe motor disability in Nepal ${ }^{1}$. It is a clinical syndrome consisting of a developmental disorder of movement and posture leading to limited activity or disability that are associated to disturbances happening in the foetus or infant brain that may be accompanied by a seizure or by disturbances of sensation, cognition, communication and behavior ${ }^{2}$. Different aetiologies occurring at different developmental staging can result in the same clinical pattern of cerebral palsy or alternatively a similar aetiology may produce variable outcomes. This clinical classification produces insufficient insight into the aetiology of cerebral palsy $^{3}$. In order to learn more about the causes and pathology of $\mathrm{CP}$, researchers have suggested the use of neuroimaging modalities such as computed tomography (CT) and magnetic resonance imaging
${ }^{1}$ Dr. Bina Prajapati Manandhar, MBBS, MD, Senior Consultant Paediatrician, Paediatric Neurology, Kanti Children's Hospital, Maharajgunj, Kathmandu, Nepal, ${ }^{2}$ Ms Usha Singh, MSc Research Methodology, Research Associate, Nepal Development Research Institute, Kathmandu, Nepal, ${ }^{3}$ Dr. Najala Khatun, MBBS, MD, Kanti Children's Hospital, Maharajgunj, Kathmandu, Nepal.

\section{Address for correspondence \\ Dr. Bina Prajapati Manandhar \\ Senior Consultant Paediatrician \\ Kanti Children's Hospital \\ Maharajgunj, Kathmandu, Nepal \\ Tel No; +977- 9851055033 \\ E-mail: prajapatibina@gmail.com}

Acknowledgements: We acknowledge $\mathrm{KCH}$ for providing permission to conduct this study.

Funding: Nil

Conflict of Interest: None

Permission from IRB: Yes

\section{How to cite}

Manandhar BP, Singh U, Khatun N. Neuroimaging in Children with Cerebral Palsy: A Study Conducted at Tertiary Level Paediatric Hospital of Nepal. J Nepal Paediatr Soc 2018;38(1):25-30.

doi: http://dx.doi.org/10.3126/jnps.v38i1.19330

This work is licensed under a Creative Commons Attribution 3.0 License.

\section{(c) (i)}


$(\mathrm{MRI})^{4,5}$. Neuroimaging modalities are rapidly evolving making significant contributions to understanding of $\mathrm{CP}$ by elaborating the underlying abnormal neuroanatomy. Neuroimaging may suggest underlying aetiology, extent and time of brain damage which are helpful for diagnostic, rehabilitative and preventive measures in these children ${ }^{6}$.

In spite of a wide range of accepted medical and rehabilitative intervention for high-risk infants and children with $\mathrm{CP}$, there is often imprecise understanding of the cause, variability in determination of treatment and inconsistency in outcome ${ }^{6}$. Studies have suggested that neuroimaging in combination with history and physical examination may improve diagnosis and management of $\mathrm{CP}^{6,7}$. Similarly, in 2004, the American Academy of Neurology published a practice parameter that supported routine neuroimaging of suspected children with $\mathrm{CP}^{8}$.

Regardless of improvement in obstetric and neonatal care; the overall prevalence of cerebral palsy has remained constant supporting the belief that pathogenesis is the primary cause mainly because of prenatal brain dysgenesis and injury ${ }^{9}$. Globally, the incidence of CP is estimated to be 2-2.5 per 1000 and it is estimated to be nearly 3 per 1000 in $\mathrm{Nepal}^{10}$. However, there is very little data regarding cerebral palsy in Nepal ${ }^{1}$. Similarly, descriptive studies in CP have been carried out in Nepal; however, those studies have not incorporated neuroimaging in $\mathrm{CP}^{1,11}$. Thus, this study aims to find out the clinical and radiological profile of children diagnosed with $\mathrm{CP}$ at a tertiary level paediatric hospital in Nepal.

\section{Material and Methods}

This study was carried out at Kanti Children's Hospital $(\mathrm{KCH})$, Maharajgunj, Kathmandu, which is the largest tertiary level government children's hospital in Nepal, most cases being referred from different parts of the country. This study was an institution based crosssectional study that utilized secondary data of children diagnosed with CP from September 2015 to April 2017. The diagnosis of CP was made by senior consultant paediatrician of Neurology in the OPD of this hospital.

CP was classified into three categories: spastic $\mathrm{CP}$, dyskinetic $\mathrm{CP}$ and ataxic $\mathrm{CP}^{12}$. . Neuroimaging findings were classified into three categories such as i) brain malformation or 1st and 2nd trimester patterns which usually occur in utero, for example, lissencephaly, pachygyria, cortical dysplasia, polymicrogyria and schizencephaly ii) periventricular white lesions, which are associated with early 3rd trimester of pregnancy and preterm born infants, for example, periventricular leukomalacia, defect following intraventricular haemorrhage or periventricular haemorrhage iii) cortical and deep grey matter lesions, which are related to late 3rd trimester or peri or neonatal, for example, basal ganglia or thalamus lesion, parasagittal injury and multicystic encephalomalacia ${ }^{13}$. Abnormalities not meeting aforementioned criteria were categorized as miscellaneous. In addition to this, variables such as child's age, gender of child, gestational age, delivery mode, birth weight, presence or absence of birth asphyxia, neonatal jaundice, visual impairment and seizure were analysed in this study.

Descriptive analysis was carried out to summarize baseline characteristics. Univariate analysis such as Chsquare test was employed for equality of proportions. In addition, Fisher's exact test and exact test for two way contingency tables with structural zeroes was employed when the cell count was less than 5 or 0 respectively ${ }^{14}$. All the analysis was carried out in SPSS version 20 .

\section{Results}

A total of 103 children were diagnosed with CP from September 2015 to April 2017. Out of these 100 children were included in this study because neuroimaging report of 3 children was not available. Nearly three quarters were male $(74 \%)$. The age group of most of children was $0-4$ years $(86 \%)$. Most of the children were born at term (90\%). About $80 \%$ of children were delivered at institution and out of them, $66 \%$ were delivered spontaneously. The birth weight of $24 \%$ of children was below 2500 grams. Microcephaly was found in $33 \%$ of children. Birth asphyxia was present in $54 \%$ of children and neonatal jaundice was seen in $21 \%$ of children. Clinical symptoms such as presence of seizure and visual impairment were present in $55 \%$ and $18 \%$ of cases respectively. Of those children who had epilepsy, the most common type of epilepsy was generalize seizure $(30 \%)$ followed by focal seizure (25\%). Out of 100 children, $21 \%$ children showed clinical features of both spastic and dyskinetic CP, therefore, they were grouped under mixed CP. Spastic CP was the most common in children $(71 \%)$, followed by mixed $(21 \%)$ and dyskinetic (8\%). For the neuroimaging test, greater percent of cases underwent CT scan (53\%) followed by MRI (47\%). Of those 100 children, $66 \%$ children had abnormal neuroimaging findings (Table 2) which included cortical or deep grey matter lesions (37\%), periventricular white matter abnormalities (23\%), miscellaneous (4\%) and brain malformation (2\%).

Univariate analysis was performed to identify the association between study variables and types of neuroimaging findings (Table 3 ). Children with miscellaneous and brain malformation were excluded 
from the analysis as they contributed only $4 \%$ and $2 \%$ of the cases respectively. From the analysis, it was found that only birth asphyxia and birth weight were significantly associated with types of neuroimaging with $p$-value $<0.05$. However, determinants such as place of delivery, neonatal jaundice, occipito-frontal circumferences, existence of seizure, types of cerebral palsy and gender of the child did not vary significantly with neuroimaging findings $(p>0.05)$.

\section{Discussion}

This study included neuroimaging findings of 100 children with $\mathrm{CP}$, out of which neuro-radiological abnormality was seen in $66 \%$ of the children. This is much lower than the findings of the studies ${ }^{4,15}$. The discrepancy in the findings is possibly because in the current study $53 \%$ of children underwent CT and it is believed that MRI is more informative compared to CT for the evaluation of patients with CP. Furthermore, of those neuroimaging abnormalities, cortical and deep grey matter contributed the highest percentage. However, a study conducted on CP found that the most common abnormality in children with $\mathrm{CP}$ was periventricular white matter lesion ${ }^{16}$. One of the reasons for differences in results may be due to the small sample size of the current study. Likewise, neuroimaging abnormality was found to be more common in spastic $\mathrm{CP}$ as in the study ${ }^{15}$. In contrast, the study carried out in Europe found neuroimaging abnormality more in ataxic $\mathrm{CP}^{17}$ and the finding of this study could not be compared with the current study because ataxic $\mathrm{CP}$ was not seen among children. Hence, further study with large sample size is required.

The current study finds a high rate of male to female ratio $(4: 1)$ and the finding of this study is similar to the studies by ${ }^{1,4}$. The male preponderance may be due to neglect or discrimination of female child in the society as majority of the patients who visited to the hospital were from low socio economic condition and rural areas of Nepal. In this study, spastic CP was found to be the most common type of CP which is consistent with the studies ${ }^{1,4,17}$. Similarly, about $8 \%$ of children had dyskinetic CP which was slightly higher compared to the study conducted in North India $(2 \%)^{4}$. This might be due to untreated or delayed in treatment of hyperbilirubinemia, which is one of the common known causes of dyskinetic. Another possible explanation could be the presence of genetic disease causing damage to basal ganglia leading to kernicterus. Findings of this study revealed that majority of children underwent CT scan, even though, MRI is more sensitive to morphologic variation, can better discriminate grey and white matter and can better identify malformation ${ }^{3}$.
Table 1: Socio-demographic characteristics of children with $\mathrm{CP}$

\begin{tabular}{lcc}
\hline Characteristics & $\begin{array}{c}\text { Frequency } \\
(\mathbf{n = 1 0 0 )}\end{array}$ & $\begin{array}{c}\text { Percentage } \\
(\mathbf{\%})\end{array}$ \\
\hline Child's age & 86 & 86 \\
\hline 0-4 years & 11 & 11 \\
\hline 5-9 years & 3 & 3 \\
\hline 10 years or above & & \\
\hline Gender of child & 74 & 74 \\
\hline Male & 26 & 26 \\
\hline Female & & \\
\hline Gestational age & 90 & 90 \\
\hline Full term & 10 & 10 \\
\hline Pre term & & \\
\hline Place of delivery & 20 & 20 \\
\hline Home delivery & 80 & 80 \\
\hline Institution delivery & &
\end{tabular}

\section{Birth weight}

\begin{tabular}{lcc}
\hline $\begin{array}{l}\text { Low birth weight } \\
(<2500 \mathrm{gm})\end{array}$ & 24 & 24 \\
\hline $\begin{array}{l}\text { Normal birth weight } \\
(>=2500 \mathrm{gm})\end{array}$ & 76 & 76
\end{tabular}

Birth asphyxia

\begin{tabular}{lll}
\hline Yes & 54 & 54 \\
\hline No & 46 & 46
\end{tabular}

\begin{tabular}{lll}
\hline Neonatal jaundice & & \\
\hline Yes & 21 & 21 \\
\hline No & 79 & 79
\end{tabular}

Occipito-frontal circumferences

\begin{tabular}{lll}
\hline Microcephaly & 33 & 33 \\
\hline Normocephaly & 67 & 67 \\
\hline Existence of seizure & & \\
\hline Yes & 55 & 55 \\
\hline No & 45 & 45
\end{tabular}

\begin{tabular}{lll} 
Visual impairment & & \\
\hline Yes & 18 & 18 \\
\hline No & 82 & 82
\end{tabular}

\section{Types of neuroimaging}

\begin{tabular}{lll}
\hline MRI & 47 & 47 \\
\hline CT scan & 53 & 53 \\
\hline
\end{tabular}

Types of palsy

\begin{tabular}{lcc}
\hline Spastic & 71 & 71 \\
\hline Dyskinetic & 8 & 8 \\
\hline Mixed & 21 & 21 \\
\hline
\end{tabular}

The possible explanation for preference of CT over MRI might be the cost of investigation as CT scan is less expensive than MRI.

The differences in the occurrence of various abnormalities in the present study as compared to 
the study conducted in North India ${ }^{4}$, periventricular changes $(23 \%$ vs $34 \%)$, cortical and deep grey matter ( $37 \%$ vs $47.8 \%)$ and malformation ( $2 \%$ vs $11.4 \%$ ) is possible because of smaller study population. CP with malformation may require alternative management, regarding subsequent pregnancies. It may also need genetic counselling and may have medico legal significance to obstetrician and neonatologist. This emphasizes the need of neuroimaging in clinically diagnosed CP children.

Table 2: Neuroimaging findings

\begin{tabular}{lcc}
\hline Types of neuroimaging findings & Frequency $(\mathbf{n = 1 0 0 )}$ & Percentage (\%) \\
\hline Normal & 34 & 34 \\
\hline Brain malformation (Lissencephaly) & 2 & 2 \\
\hline Periventricular white matter abnormalities & 23 & 23 \\
\hline Cortical or deep grey matter abnormalities & 37 & 37 \\
\hline Miscellaneous & 4 & 4 \\
\hline
\end{tabular}

Table 3: Association between study variables and neuroimaging findings

\begin{tabular}{|c|c|c|c|c|}
\hline Characteristics & $\begin{array}{l}\text { Normal } \\
\text { n1 (\%) }\end{array}$ & $\begin{array}{c}\text { Periventricular white matter } \\
\text { abnormalities n2 (\%) }\end{array}$ & $\begin{array}{l}\text { Cortical or deep grey } \\
\text { abnormalities n3 (\%) }\end{array}$ & $p$-value \\
\hline Gestational age & & & & 0.126 \\
\hline Full term & $30(88.2)$ & $19(82.6)$ & $36(97.3)$ & \\
\hline Pre term & $4(11.8)$ & $4(17.4)$ & $1(2.7)$ & \\
\hline Place of delivery & & & & 0.150 \\
\hline Home delivery & $8(23.5)$ & $7(30.4)$ & $4(10.8)$ & \\
\hline Institutional delivery & $26(76.5)$ & $16(69.6)$ & $33(89.2)$ & \\
\hline Birth asphyxia & & & & $0.001^{*}$ \\
\hline Yes & $11(32.4)$ & $14(60.9)$ & $28(75.7)$ & \\
\hline No & $23(67.6)$ & $9(39.1)$ & $9(24.3)$ & \\
\hline Neonatal jaundice & & & & 0.389 \\
\hline Yes & $9(26.5)$ & $5(21.7)$ & $5(13.5)$ & \\
\hline No & $25(73.5)$ & $18(78.3)$ & $32(86.5)$ & \\
\hline Occipito frontal circumferences & & & & 0.142 \\
\hline Microcephaly & $8(23.5)$ & $8(34.8)$ & $17(45.9)$ & \\
\hline Normocephaly & $26(76.5)$ & $15(65.2)$ & $20(54.1)$ & \\
\hline Existence of seizure & & & & 0.195 \\
\hline Yes & $14(41.2)$ & $13(56.5)$ & $23(62.2)$ & \\
\hline No & $20(58.8)$ & $10(43.5)$ & $14(37.8)$ & \\
\hline Type of cerebral palsy & & & & 0.268 \\
\hline Spastic & $21(61.8)$ & $20(87)$ & $28(75.7)$ & \\
\hline Dyskinetic & $4(11.8)$ & 0 & $3(8.1)$ & \\
\hline Mixed & $9(26.5)$ & $3(13)$ & $6(16.2)$ & \\
\hline Birth weight & & & & $0.001^{*}$ \\
\hline Low birth weight $(<2500 \mathrm{gm})$ & $6(17.6)$ & $12(52.2)$ & $4(10.8)$ & \\
\hline Normal birth weight ( $\geq 2500 \mathrm{gm})$ & $28(82.4)$ & $11(47.8)$ & $33(89.2)$ & \\
\hline Gender of child & & & & 0.22 \\
\hline Male & $24(70.6)$ & $20(87)$ & $25(67.6)$ & \\
\hline Female & $10(29.4)$ & $3(13)$ & $12(32.4)$ & \\
\hline
\end{tabular}

Note: $p$-value in italic was calculated from Exact test for two way contingency tables with structural zeroes *statistically significant at $\mathrm{p}<5 \%$. 
The result of this study revealed that birth asphyxia was more common among children with neurological abnormalities such as periventricular changes and cortical and deep grey matter compared to normal neuroimaging finding. Furthermore, this result was supported by univarite analysis which found significant association between birth asphyxia and types of neuroimaging findings. Similarly, findings on MRI suggested three MRI patterns: periventricular leukomalacia, basal ganglia or thalamus lesions and multicystic encephalopathy, all of which are primarily associated with hypoxic brain injury ${ }^{18}$. Likewise, this study also finds significant difference between birth weight and neuroimaging patterns. This may be because neuroimaging pattern such as periventricular leukomalacia are usually detected in low birth weight infants and cortical and grey matter abnormalities are seen in term infants ${ }^{19}$. However, strength of association between birth weight and neuro-radiological abnormality is not measured in this study. There is no significant difference in periventricular changes and cortical and deep grey matter abnormalities with respect to gestational age of children whereas a study conducted in Germany ${ }^{5}$ reported higher percentage

\section{References}

1. Thapa R. Retrospective descriptive study of cerebral palsy in Nepal. J Autism Dev Disord 2016;46(7):228591. DOI: https://doi.org/10.1007/s10803-016-2757-x.

2. Rosenbaum $P$, Paneth $N$, Leviton $A$, et al. A report: the definition and classification of cerebral palsy April 2006. Dev Med Child Neurol Suppl 2007;109(Suppl 109):8-14. DOI: 10.1111/j.1469-8749.2007.tb12610.x.

3. Korzeniewski SJ, Birbeck G, DeLano MC, Potchen MJ, Paneth N. A systematic review of neuroimaging for cerebral palsy. J Child Neurol 2008;23(2):216-27. DOI: https://doi.org/10.1177/0883073807307983

4. Aggrawal A, Mittal H, Dbenath SKR, Rai A. Neuroimaging in Cerebral Palsy-Report from North India. Iran J child Neurol 2013;7(4):41.

5. Krägeloh-Mann I, Horber V. The role of magnetic resonance imaging in elucidating the pathogenesis of cerebral palsy: a systematic review. Dev Med Child Neurol 2007;49(2):144-51. DOI: https://doi. org/10.1111/j.1469-8749.2007.00144.x.

6. Accardo J, Kammann H, Hoon Jr AH. Neuroimaging in cerebral palsy. J Pediatr 2004;145(2):S19-27. DOI: http://dx.doi.org/10.1016/j.jpeds.2004.05.018.

7. Novacheck TF, Trost JP, Sohrweide S. Examination of the child with cerebral palsy. Orthop Clin 2010;41(4):469-88. DOI: https://doi.org/10.1016/j. ocl.2010.07.001. of periventricular changes in preterm and grey matter and cortical abnormalities in term babies. However, the decrease number of preterm may be the reason for decreased frequency of periventricular changes in the current study.

This study was limited to only one hospital, therefore; the findings of this study may not be generalized. Similarly, due to small sample size, statistically significant relation between the study variables was limited to only two variables.

\section{Conclusion}

The result of this study suggests that neuroimaging correlates with clinical findings and also helps in revealing the pathological condition. Thus, neuroimaging will help parents and physicians to better understand the condition of children and to predict their necessity in the future. Therefore, this study suggests that all children with CP should need to undergo MRI scan. Similarly, the application of neuroimaging to CP children within Nepal is still at early phase; hence, further studies are needed to better understand neurological patterns in children with $\mathrm{CP}$

8. Ashwal S, Russman BS, Blasco PA, et al. Practice parameter: diagnostic assessment of the child with cerebral palsy: report of the Quality Standards Subcommittee of the American Academy of Neurology and the Practice Committee of the Child Neurology Society. Neurology 2004;62(6):851-63. DOI: https:// doi.org/10.1212/01.WNL.0000117981.35364.1B.

9. Hoon Jr AH. Neuroimaging in cerebral palsy: patterns of brain dysgenesis and injury. J Child Neurol 2005;20(12):936-9. DOI: https://doi.org/10.1177/088 30738050200120201

10. Cerebral Palsy Nepal. Cerebral Palsy \& Nepal [Internet]. 2018 [cited 2018 Feburary 4]. Available from: http://www.cpnepal.org/cerebral-palsy-in-nepal/.

11. Saul R, Phillips D. Ghosts and germs: Cerebral Palsy in Nepal: A preliminary exploration of cosmology and disability. CNAS 1998;25(2);215-32.

12. Cans C. Surveillance of cerebral palsy in Europe: a collaboration of cerebral palsy surveys and registers. Dev Med Child Neurol 2000;42(12):816-24. DOI: 10.1111/j.1469-8749.2000.tb00695.x.

13. Krägeloh-Mann I. Imaging of early brain injury and cortical plasticity. Exp Neurol 2004;190:84-90. DOI:https://doi.org/10.1016/j.expneurol.2004.05.037.

14. Landau S, Everitt BS. A handbook of statistical analyses using SPSS. Boca Raton, FL: Chapman \& Hall/CRC, 2004.

15. Robinson MN, Peake LJ, Ditchfield MR, Reid SM, Lanigan A, Reddihough DS. Magnetic resonance 
imaging findings in a population-based cohort of children with cerebral palsy. Dev Med Child Neurol 2009;51(1):39-45. DOI: https://doi.org/10.1111/j.14698749.2008.03127.x

16. Yoon $\mathrm{BH}$, Romero R, Park JS, et al. Fetal exposure to an intra-amniotic inflammation and the development of cerebral palsy at the age of three years. Am J Obstet Gynecol 2000;182(3):675-81. DOI: https://doi. org/10.1067/mob.2000.104207.

17. Bax M, Tydeman C, Flodmark O. Clinical and MRI correlates of cerebral palsy: the European Cerebral
Palsy Study. JAMA 2006;296(13):1602-8. DOI: https://doi.org/10.1001/jama.296.13.1602.

18. Cabaj A, Bekiesińska-Figatowska M, Mądzik J. MRI patterns of hypoxic-ischemic brain injury in preterm and full term infants-classical and less common MR findings. Polish J Radiol 2012;77(3):71. DOI: http:// dx.doi.org/10.12659/PJR.883379.

19. Plaisier A. MR Imaging of the Preterm Brain: Safer better faster stronger [Internet]. Erasmus University Rotterdam;2014. Available from: http://hdl.handle. net/1765/50825. 